\title{
ІНДУКТОР ДЛЯ ОПРОМІНЕННЯ ЗЛОЯКІСНИХ ПУХЛИН
}

Стегній В.В.

vladstegniy55555@gmail.com

Національний технічний університет України «Київський політехнічний інститут імені Ігоря Сікорського»,

м. Київ, Україна

Дасюкевич О.Й., к.б.н. olgadix1993@gmail.com

Національний інститут раку,

м. Київ, Україна

Рихальський О.Ю.

alex@kpi.ua

Національний інститут раку,

м. Київ, Україна

Шейн І. В., к.ф.-м.н.

i.sheina@karazin.ua

Харківський національний університет імені В. Н. Каразіна,

м. Харків, Україна

Цвір Д.А.,

tsvir.d@gmail.com,

Приватне "Науково-виробниче підприємство "АТ-система".

м. Київ, Україна

Орел В.Е., проф., д.б.н.,

valeriiorel@gmail.com

Національний інститут раку,

Національний технічний університет України «Київський політехнічний інститут імені Ігоря Сікорського»,

м. Київ, Україна

Реферат - Розроблено конструкцію та підібрано матеріали індуктора для опромінення злоякісних пухлин. Виміряно просторовий розподіл магнітного поля індуктора. Побудовано $3 D$ модель для подальшого комп'ютерного планування магнітного опромінення пухлини. За допомогою Comsol Multiphysics, проаналізовано теплові та магнітні характеристики приладу. У результаті проведеного дослідження впливу магнітного поля наднизької частоти (50 Ги) на перещеплену піддослідним шурам карииносаркому Уоркер-256 було виявлено збільшення на 22\% коефіцієнту гальмування кінетики росту пухлини. Температура пухлини під час опромінення не перевищувала $33{ }^{\circ} \mathrm{C}$.

Ключевые слова - магнітне поле; комп'ютерне моделювання, індуктор, протипухлинний ефект, карииносаркома Уоркер-256.

\section{І. ВСТУП}

Рак $є$ другою провідною причиною смерті у світі. Кількість зареєстрованих летальних випадків у 2018 році досягла 18 мільйонів у всьому світі. За прогнозами Всесвітньої організації охорони здоров'я (ВОО3) до 2030 року кількість летальних випадків раку збільшиться щонайменше на $70 \%$ [1]. Сучасні методи лікування злоякісних пухлин, такі як хірургічне втручання, хіміотерапія, радіотерапія, імунотерапія, гормональна терапія, істотно пов'язані 3 обмеженнями щодо призначення та мають побічні ефекти [2].

Тому існує гостра потреба у розробці терапевтичних біоінженерних технологій, зокрема, 3 використанням змінних електромагнітних полів у діапазоні 0-300 Гц. У галузі медичних технологій лікування раку такий метод відомий як магнітна стимуляція низькочастотним полем i вже був застосований при терапії різних типів раку, включаючи рак шкіри, грудної залози, простати, гепатоцелюлярний, легень, яєчників, підшлункової залози, сечового міхура, 
щитоподібної залози та товстої кишки. У доклінічних дослідженнях in vitro та in vivo показано, що магнітні поля (МП) мають протипухлинну дію, не пов'язану з тепловими ефектами. Однією 3 потенційних переваг такого підходу є те, що магнітні поля завдають меншої шкоди нормальним тканинам [3].

Механізми і терапевтичну ефективність МП можна пояснити збільшенням генерації активних форм кисню (АФК) та зміною захисних антиоксидантних систем. Вплив ендогенних або екзогенних окисників, таких як гідроксильний радикал $(\bullet \mathrm{OH})$, перекис водню $\left(\mathrm{H}_{2} \mathrm{O}_{2}\right)$ та супероксидний радикал $\left({ }^{\circ} \mathrm{O}_{2}{ }^{-}\right)$, є ключовою особливістю будь-якої біологічної системи. Отже, баланс між процесами окислення та відновлення стає життєво важливим. Антиоксидантні можливості організму-господаря включають як ферментативні, так i неферментативні механізми. Ракові клітини можуть використовувати окисно-відновну сигналізацію для ініціації некрозу та апоптозу пухлини [4].

Існують моделі апаратів для магнітотерапії 3 нетепловим ефектом, які використовуються у клінічній практиці при лікуванні онкологічних захворювань, засновані на використанні надзвичайно низькочастотних вихрових магнітних полів $(20-150 \quad$ Гц $) \quad 3 \quad$ індукцією $1-5$ мТл для опромінення всього тіла пацієнта $[5,6]$. Такі пристрої, як правило, складаються 3 індуктора, перетворювача частоти 3 фільтром, персонального комп'ютера та рухомої кушетки для пацієнта.

У жовтні 2015 року Управління 3 контролю за продуктами і ліками (FDA) США змінило класифікацію виробів медичного призначення - терапевтичні пристрої пульсуючих електромагнітних полів 3 категорії 3 у категорію 2. Цей крок FDA обумовлений заявою фахівців щодо необхідності їхнього спеціального призначення лікарем для застосування [7]. Ймовірно, на дане рішення вплинула нестача вичерпної інформації про просторовий розподіл та терапевтичну дію низькочастотного магнітного поля.

\section{II. МЕТА ДОСЛІДЖЕННЯ}

У даній статті наводиться конструкція індуктора для опромінення злоякісних пухлин, результати експериментального дослідження та комп'ютерного моделювання розподілу параметрів надзвичайно низькочастотного магнітного поля індуктора та його вплив на кінетику росту карциносаркоми Уоркер-256.

\section{III. КОНСТРУКЦІЯ ТА ФІЗИКО- ТЕХНІЧНІ ПАРАМЕТРИ ІНДУКТОРА}

На рис. 1 показано загальний вид та розміри індуктора. Він містить соленоїдну котушку 13 обмоткою 2, магнітопровід, виконаний з двох гнучких гілок 3 і 4, нижні кінці 5 і 6, якого зібрано в осерді 7 внапуск i закріплено за допомогою вставок 83 феромагнітного матеріалу.
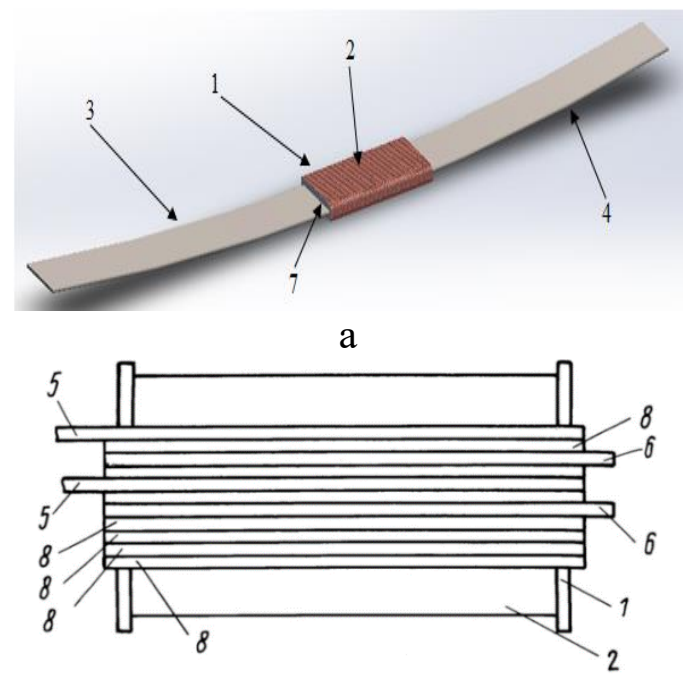

6

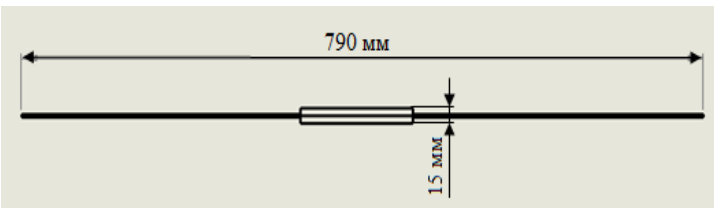

B

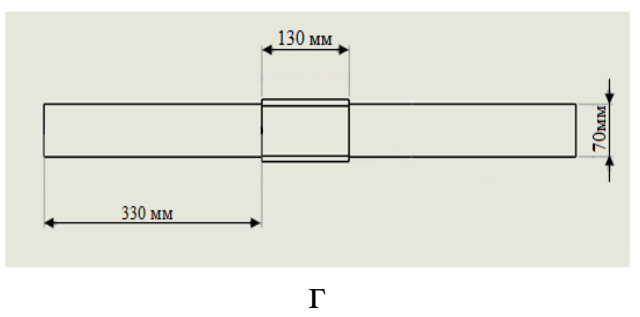

Рис.1. Загальний вид (а), конструкційні особливості [6] (б) та розміри індуктора (в,г).

Індуктор працює наступним чином (рис. 2.), між гнучкими гілками 3 та 4 магнітопроводу розміщується ділянка тіла, уражена злоякісною пухлиною 12 , яка 
піддається магнітному опроміненню. Оскільки гілки дугоподібні і пружні, вони щільно охоплюють розташовану між ними частину тіла 12. Потім підключають котушку 1 до джерела струму i, змінюючи його величину, встановлюють напруженість магнітного поля, необхідну для лікування.

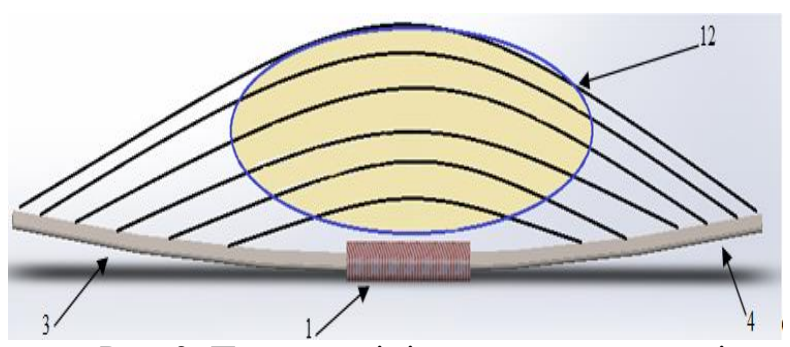

Рис. 2. Принцип дії індуктора для опромінення магнітним полем злоякісної пухлини.

Відповідно до фізико-технічних параметрів магнітного поля, було здійснено підбір конструкційних матеріалів та проведено необхідні розрахунки. Фізикотехнічні характеристики індуктора наведено в табл. 1.

Таблиця 1. Фізико-технічні характеристики індуктора

\begin{tabular}{|l|c|}
\hline \multicolumn{1}{|c|}{ Характеристика } & Значення \\
\hline $\begin{array}{l}\text { Діаметр провідника } \\
\text { обмотки }\end{array}$ & 0,2 мм \\
\hline Матеріал провідника & $\begin{array}{c}\text { Мідний дріт марки } \\
\text { ПЕВ-1 }\end{array}$ \\
\hline $\begin{array}{l}\text { Матеріал } \\
\text { магнітопроводу }\end{array}$ & $\begin{array}{c}\text { Електротехнічна сталь } \\
\text { Т090-27P }\end{array}$ \\
\hline Матеріал осердя & $\begin{array}{c}\text { Електротехнічна сталь } \\
\text { Т090-27P }\end{array}$ \\
\hline $\begin{array}{l}\text { Площа перетину } \\
\text { провідника }\end{array}$ & $4,16^{*} 10^{-8}$ м $^{2}$ \\
\hline Кількість витків & 44806 \\
\hline Вихідна потужність & До 19 Вт \\
\hline Струм у котушці & $0,078 \mathrm{~A}$ \\
\hline $\begin{array}{l}\text { Напруга, що } \\
\text { подається на котушку }\end{array}$ & $220 \mathrm{~B}$ \\
\hline Частота & 50 Гц \\
\hline
\end{tabular}

3 метою створення достовірної моделі індуктора для подальшого комп'ютерного планування магнітного опромінення злоякісних пухлин, було проведено вимірювання просторового розподілу магнітного поля. Для цього поверхню індуктора було розділено на 140 точок, у яких здійснювалось вимірювання. Вимірювання магнітного поля проводилось за допомогою магнітометра MH-17(PTS Josef Solnar).

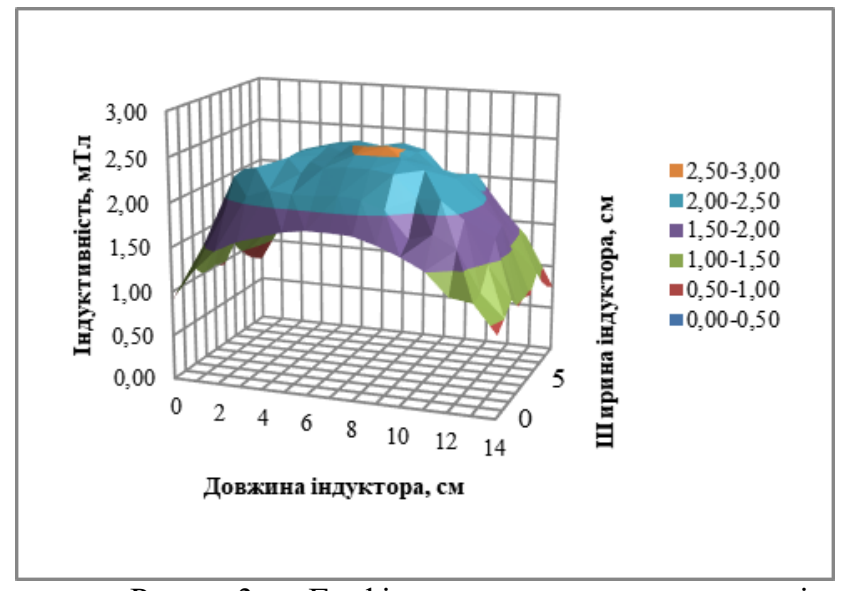

Рис. 3. Графік просторового розподілу магнітного поля індуктора.

Після статистичної обробки виміряних даних магнітного поля було отримано наступні результати: середнє значення $\mathrm{M}=$ 1,85 мТл, коефіцієнт асиметрії $\mathrm{A}=-0,477$. На підставі чого можна зробити висновок, що магнітне поле неоднорідне 3 максимумом на середині котушки - 2,56 мТл.

\section{IV. КОМП'ЮТЕРНЕ МОДЕЛЮВАННЯ МАГНІТНОГО ПОЛЯ}

Комп'ютерне моделювання за допомогою програмного забезпечення Comsol Multiphysics 5.4 складалось 3 наступних чотирьох етапів: побудова 3D моделі пухлини та оточуючих іiі тканин 3 урахуванням геометрії індуктора; задання параметрів магнітного опромінення тканин; задання температурних параметрів повітря $-20^{\circ} \mathrm{C}$, тканин $-36^{\circ} \mathrm{C}$, крові $-37^{\circ} \mathrm{C}$; розподіл моделі на кінцеві елементи та побудова сітки для аналізу; аналіз результатів комп'ютерного планування.

Розрахунок магнітного поля проводився на основі рівнянь Максвела [8], а розподіл температури визначали за допомогою рівнянь теплопровідності [9].

На рис. 4. наведено 3D модель пухлини та оточуючих ऑii тканин. Відповідно до розрахунків, результати яких наведені на рис. 5 , величина магнітного поля індуктора та у пухлині при струмі в індукторі 79 мА, напрузі 
220 В, частоті 50 Гц дорівнює, у середньому, 6 мТл. Температура шкіри, жирової тканини та пухлини (рис. 6) змінюються, у середньому, протягом часу опромінення (30 хвилин) на $4^{\circ} \mathrm{C}$, $з 33$ до $37^{\circ} \mathrm{C}$, що може бути спричинено теплообміном 3 індуктором, температура індуктора змінюється $320^{\circ} \mathrm{C}$ до $48^{\circ} \mathrm{C}$, тобто різниця його температур складає $28^{\circ} \mathrm{C}$.

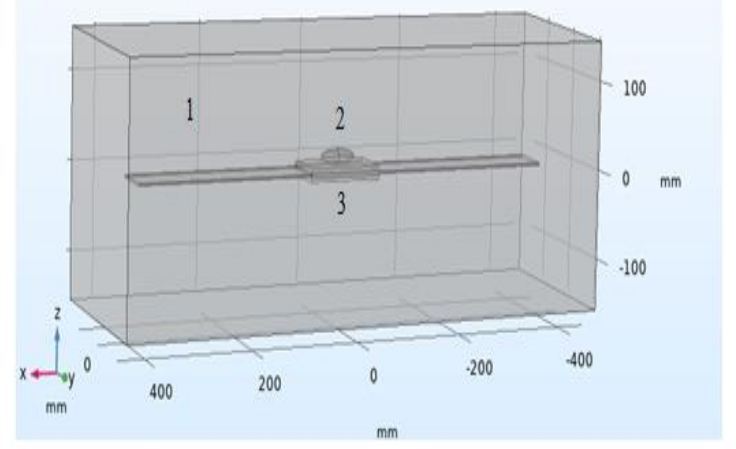

a

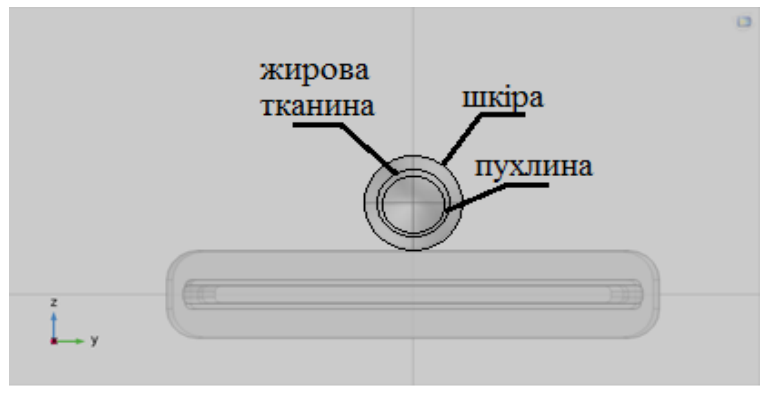

6

Рис. 4. 3D (a) та 2D (б) моделі пухлини та оточуючих iї тканин: 1 - середовище (повітря), 2тришаровий біооб'єкт (1-й шар - шкіра, 2-й - жирова тканина, 3-й - пухлина), 3 - індуктор.

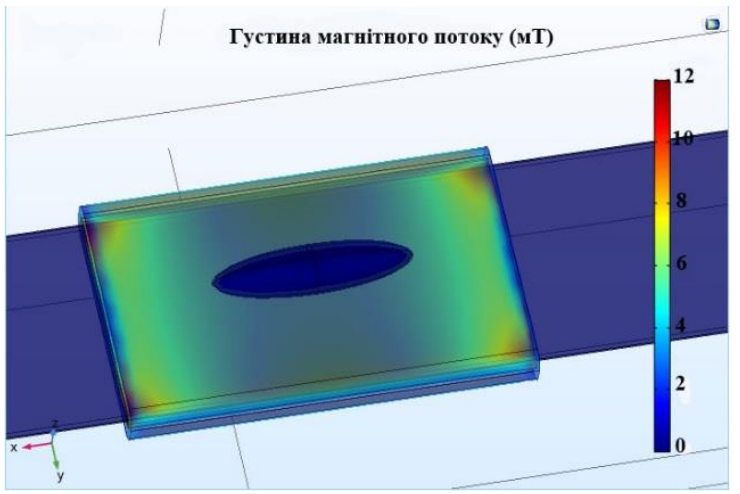

Рис. 5. Розподіл магнітного поля (мТл).

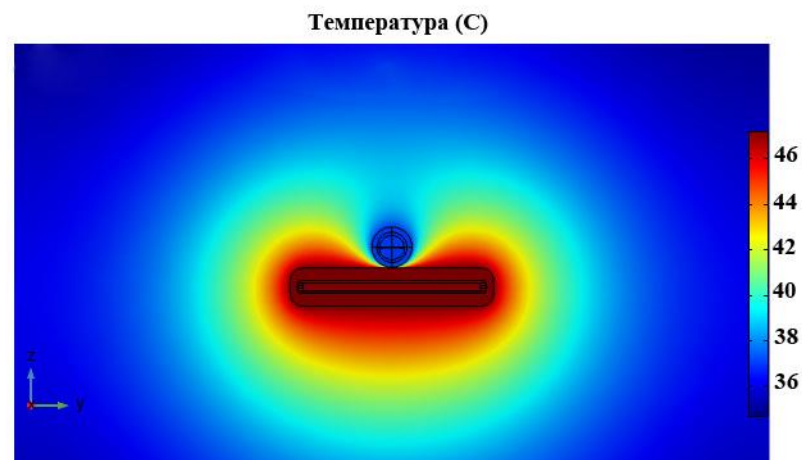

Рис. 6. Розподіл температури $\left({ }^{\circ} \mathrm{C}\right)$.

Проаналізувавши результати розрахунку полів у Comsol Multiphysics на побудованій 3D моделі індуктора 3 пухлиною, можна зробити наступні висновки: магнітне випромінювання майже не змінюе температуру пухлини та оточуючих її тканин. Зміна температури відбувається внаслідок теплообміну з індуктором, який протягом часу опромінення суттєво нагрівається. Величина теоретично розрахованого магнітного поля, у середньому дорівнює 6 мТл, порядок якої наближається до вищенаведеної експериментально отриманої величини.

\section{V. ЕКСПЕРИМЕНТАЛЬНЕ ДОСЛІДЖЕННЯ ПРОТИПУХЛИННОЇ ДІЇ ІНДУКТОРА}

У дослідженні було використано щурівсамиць неінбредних ліній тварин, вагою $140 \pm 3$ г розводки віварію Національного інституту раку. Імплантацію карциносаркоми Уокер-256 проводили шляхом введення щурам у праве стегно $2 * 10^{6}$ клітинних суспензій об'ємом 200 мкл у середовищі 199. Тварини були випадковим чином розподілені між групами (n = 10 тварин у групі): група 1 контроль (без лікування); група 2 - вплив магнітного поля.

Лікування проводилося через 2 дні після перещеплення пухлини шляхом тотального опромінення щурів. Опромінювання МП проводили, коли тварини знаходилися у нерухомому положенні, лежачи на індукторі протягом 80 хв під загальним знеболенням (інгаляція ізофлурану 1-2\%). Для моніторингу температури всередині та на поверхні пухлин було використано волоконнооптичні термометри ТМ-4 (Радмір). Температура пухлини під час опромінення не перевищувала $33{ }^{\circ} \mathrm{C}$. 
Протоколи

$$
\text { дослідження }
$$

на лабораторних тваринах відповідали Закону України № 3447 - IV "Про захист тварин від жорстокого поводження" та Європейській директиві 2010/63/СС "Про захист тварин, які використовуються у наукових цілях".

Для оцінки нелінійної динаміки росту пухлин тварин використовували фактор росту $\varphi$ за автокаталітичним рівнянням:

$$
d x / d t=\varphi\left(x+x_{0}\right)(1-x)
$$

де $x=\left(\Phi-\Phi_{0}\right) /\left(\Phi_{\infty}-\Phi_{0}\right)$ - відносний ріст пухлини у момент часу $\mathrm{t}$;

$x_{0}=\Phi_{0} /\left(\Phi_{\infty}-\Phi_{0}\right)$ - відносний об'єм пухлини у момент часу $\mathrm{t}=0$;

$\Phi_{0}$ та $\Phi_{\infty}$ - початковий і граничний

обсяг пухлини, відповідно;

$\Phi$ - об'єм пухлини у момент часу t [10].

Вплив протиракової магнітотерапії на нелінійну динаміку росту пухлин тварин оцінювали за коефіцієнтом гальмування:

$$
\kappa=\varphi_{c} / \varphi_{e},
$$

де $\varphi_{c}$ - фактор росту для контрольної групи тварин; групи.

$$
\varphi_{\mathrm{e}} \text { - фактор росту для досліджуваної }
$$

Статистичний аналіз вірогідності отриманих даних проводили за допомогою $\mathrm{t}$ критерію Стьюдента 3 попередньою перевіркою гіпотези про нормальний закон розподілу випадкової величини за критерієм Колмогорова-Смірнова. Для аналізу даних було використано пакет прикладних програм Statistic 11.0 та Prism 8.0.

Рис. 7 та табл. 2 демонструють вплив опромінення МП на ріст карциносаркоми Уокер-256. Отримані результати виявили суттєву різницю між контролем без лікування i групою, що зазнала впливу опромінення. Коефіцієнт гальмування кінетики росту пухлини під впливом МП був на 22\% вищий. На 20 день після імплантації пухлини 70\% тварин після впливу магнітотерапії були живими, тоді як усі щури у контрольній групі (без лікування) загинули.

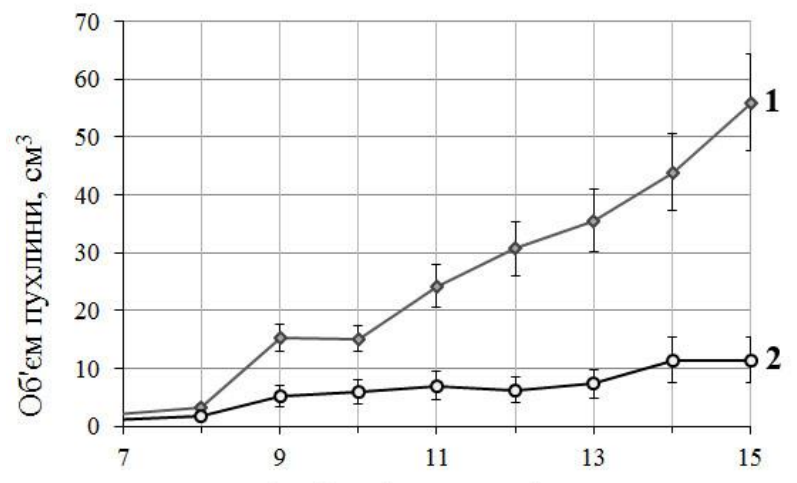

Доба після імплантації пухлини

Рис. 7. Кінетика росту карциносаркоми Уокер256 (M \pm m): Група 1 - контроль (без лікування); 2 опромінення МП.

Таблиця 2. Кінетика росту на 15 день після імплантації карциносаркоми Уокер-256

\begin{tabular}{|l|c|c|}
\hline Група тварин & $\begin{array}{c}1 \\
(\mathrm{n}=10)\end{array}$ & $\begin{array}{c}2 \\
(\mathrm{n}=10)\end{array}$ \\
\hline Експеримент & $\begin{array}{c}\text { Контроль, } \\
\text { без } \\
\text { лікування }\end{array}$ & $\begin{array}{c}\text { Опромінення } \\
\text { МП }\end{array}$ \\
\hline $\begin{array}{l}\text { Фактор росту } \varphi, \\
\text { день }\end{array}$ & $0,73 \pm 0,02$ & $0,60 \pm 0,09^{*}$ \\
\hline $\begin{array}{l}\text { Коефіцієнт } \\
\text { гальмування, } \kappa\end{array}$ & 1 & 1,22 \\
\hline
\end{tabular}

\section{VI. ЗАКЛЮЧЕННЯ}

Таким чином, на основі фізикотехнічних параметрів складових індуктора для опромінення злоякісних пухлин, котушки індуктивності та магнітопроводу (осердя), а також фізичних параметрів магнітного поля було здійснено підбір конструкційних матеріалів і проведено необхідні розрахунки. При цьому концептуально ідея конструкції полягала у необхідності ініціювати просторово неоднорідне магнітне поле, що було обумовлено однією 3 добре відомих характерних властивостей злоякісних пухлин - їхньою високою гетерогенністю. Згідно 3 основами теорії нелінійної динаміки, можливо висунути гіпотезу, що неоднорідне магнітне поле матиме найбільш виражений протипухлинний ефект. Отримані результати можна розглядати як наслідок змін у нелінійній динаміці редокс сигналізації під впливом неоднорідного МП, що визначило 
ступінь некрозу та апоптозу злоякісних клітин [11].

3 метою побудови достовірної 3D моделі для подальшого комп'ютерного планування магнітного опромінення пухлини індуктором за допомогою Comsol Multiphysics, було проаналізовано його геометричні характеристики, принцип роботи, також було виміряно величину магнітного поля та досліджено його неоднорідний розподіл.

Проведені випробування на тваринній моделі злоякісної пухлини засвідчили, що магнітне опромінення майже не змінює температуру пухлини та оточуючих іiі тканин, зміна температури відбувається внаслідок теплообміну з індуктором, який протягом часу опромінення достатньо суттєво нагрівається, однак різниця температур на початку та наприкінці опромінення складає $28^{\circ} \mathrm{C}$; величина магнітного поля, у середньому, дорівнює 6 мТл, що відповідає інформації 3 літературних джерел стосовно ефектів низькочастотних полів у діапазоні мТл [12].

Дослідження біологічного впливу магнітного поля на карциносаркому Уокер-256 показало, що у щурів за умов обраних параметрів опромінення магнітним полем, у якості єдиного методу лікування пухлини, коефіцієнт гальмування кінетики росту пухлини був на $22 \%$ вищим.

\section{ПЕРЕЛІК ПОСИЛАНЬ}

[1] Ferlay J . Estimating the global cancer incidence and mortality in 2018: GLOBOCAN sources and methods/ J .Ferlay, M .Colombet, I. Soerjomataram, C.Mathers, D.M. Parkin, M. Pineros , A.Znaor, F. Bray // Int J Cancer. -2019. - 144, P. 19411953. doi: 10.1002/ijc.31937.

[2] Bailly C. Potential use of edaravone to reduce specific side effects of chemo-, radio- and immuno-therapy of cancers / C. Bailey // Int Immunopharmacol. - 2019. - Vol. 77. - P. 105967. doi: 10.1016/j.intimp.2019.105967

[3] Mechanisms and therapeutic effectiveness of pulsed electromagnetic field therapy in oncology / M. Vadala, J. Cesar, M. A. Vallelunga [et. al] // Cancer Med. - 2016. - Vol. 5, № 11. - P. 3128-3139.

[4] Liou G.Y. Reactive oxygen species in cancer / G. Y. Liou, P. Storz // Free Radic Res. - 2010. - Vol. 44, P. - 479-496. doi: $10.3109 / 10715761003667554$

[5] Шишкин С. Магнитотерапевтические установки и аппараты отечественного производства / Сергей Шишкин. // Современная электроника. - 2015. - №4. - С. 10-15;

[6] Шаргородский В. С. Индуктор для магнитотерапии [Електронний ресурс] / В. С. Шаргородский, Л. Г. Сафонов, Л. Л. - 1996. - Режим доступу до ресурсу: http://www.freepatent.ru/patents/2051704

[7] General Wellness: Policy for Low Risk Devices - Guidance for Industry and Food and Drug Administration Staff (PDF). U.S. Food and Drug Administration. 29 July 2016. Retrieved 16 February 2016.
[8] Максвелл Дж. К. Избранные сочинения по теории электромагнитного поля. - М.: ГИТТЛ, 1952. — 687 с.

[9] Crank, J. A Practical Method for Numerical Evaluation of Solutions of Partial Differential Equations of the HeatConduction Type / J. Crank, P. Nicolson, D. R. Hartree // Proceedings of the Cambridge Philosophical Society. - 1947. Vol. 43. - P. 50-67.

[10] Emanuel N. Kinetics of experimental tumor processes. Oxford: Pergamon Press, 1982,ISBN-13:978-0080249094

[11] Орел В. Э. Хаос и рак, механохимия и механоэмиссия. Киев. Телеоптик, 2002. - 295с.

[12] Effect of magnetic fields on tumor growth and viability / I. Tatarov, A. Panda, D. Petkov [et al] // Comp. Med. - 2011. Vol. 61. - P. 339-345. 


\section{ИНДУКТОР ДЛЯ ОБЛУЧЕНИЯ ЗЛОКАЧЕСТВЕННЫХ ОПУХОЛЕЙ}

Стегний В.В.

vladstegniy55555@@gmail.com

Национальный технический университет Украины «Киевский политехнический институт им. Игоря Сикорского»,

г. Киев, Украина

Дасюкевич О.И., к.б.н. olgadix1993@gmail.com

Национальный институт рака,

г. Киев, Украина

Рыхальский А.Ю.

alex@kpi.ua

Национальный институт рака,

г. Киев, Украина

Шейн И. В., к.ф.-м.Н

i.sheina@karazin.ua

Харьковский национальный университет им. В. Н. Каразина,

г. Харьков, Украина

Цвир Д.А.,

tsvir.d@gmail.com

Частное "Научно-производственное предприятие "АТ-система".

г. Киев, Украина

Орел В.Э., проф., д.б.н.,

valeriiorel@gmail.com

Национальный институт рака,

Национальный технический университет Украины «Киевский политехнический институт им. Игоря Сикорского»,

г. Киев, Украина

Реферат - Разработана конструкиия и подобраны материалы индуктора для облучения злокачественных опухолей. Проведено измерение пространственного распределения магнитного поля индуктора. Построена $3 D$ модель для дальнейтего компьютерного планирования магнитного облучения опухоли. C помощььо Comsol Multiphysics, проанализированы тепловые и магнитные характеристики прибора. В результате проведенного исследования влияния магнитного поля сверхнизкой частоты (50 Ги) на имплантированную подопытным крысам карииносаркому Уоркер-256 было обнаружено увеличение коэффициента торможения кинетики роста опухоли на 22\%. Температура в опухоли во время облучения не превымала $33^{\circ} \mathrm{C}$.

Ключевые слова - магнитное поле; компьютерное моделирование, индуктор, противоопухолевый эффект, карииносаркома Уоркер-256. 


\title{
THE INDUCTOR FOR MALIGNANT TUMOR IRRADIATION
}

Stegnii V.V.

vladstegniy555550@gmail.com National Technical University of Ukraine «Igor Sikorsky Kyiv Polytechnic Institute»,

Kyiv, Ukraine

Dasukevich O.J., Ph.D. olgadix1993@gmail.com National Cancer Institute,

Kyiv, Ukraine

Rykhalskyi O.Yu. alex@kpi.ua

National Cancer Institute,

Kyiv, Ukraine

Shein I.V., Ph.D.

i.sheina@karazin.ua

V. N. Karazin Kharkiv National University,

Kharkiv, Ukraine.

Tsvir D.A.,

tsvir.d@gmail.com

Private research and manufacture enterprise "AT System".

Kyiv, Ukraine

Orel V.E., Professor, Dr. Sci. valeriiorel@gmail.com

National cancer institute, National Technical University of Ukraine «Igor Sikorsky Kyiv Polytechnic Institute»,

Kyiv, Ukraine

\begin{abstract}
The current study was undertaken to design and construct a super low frequency generating inductor for malignant tumor irradiation. The spatial distribution of the magnetic field produced by the inductor was measured to build a 3D model for magnetic irradiation treatment planning. Comsol Multiphysics was adopted to analyze temperature and magnetic characteristics of the device. The obtained results showed that the influence of a super low frequency magnetic field (50 Hz) on Walker-256 carcinosarcoma, an experimental tumor model in rodents, bearing animals caused a $22 \%$ increase in the braking ratio of tumor growth kinetics. The temperature inside the tumor during irradiation did not exceed $33^{\circ} \mathrm{C}$.
\end{abstract}

Key words - magnetic field, computer-assisted modelling, inductor, antitumor effect, Walker-256 carcinosarcoma. 